\title{
URBAN MICROCLIMATE IMPROVEMENT USING ENVI-MET CLIMATE MODEL
}

\author{
E. Chatzinikolaou ${ }^{1, *}$, C. Chalkias $^{2}$, E. Dimopoulou ${ }^{1}$ \\ ${ }^{1}$ School of Rural and Surveying Engineering, National Technical University of Athens, \\ Iroon Polytechneiou str 9, Zografou 15780 - e.chatz175@gmail.com, efi@ survey.ntua.gr \\ ${ }^{2}$ Department of Geography, Harokopio University, El. Venizelou 70, Athens 17671, Greece- xalkias@ hua.gr
}

\author{
Commission IV, WG IV/10
}

KEY WORDS: Urban Microclimate, simulation, vegetation scenarios, 3D geo-information, GIS, ENVI-met climate model

\begin{abstract}
:
The aim of this paper is the modelling of urban microclimate, based on the limits imposed by the complexity of the threedimensional space of cities. To this purpose, different Bioclimatic Scenarios were investigated through the microclimatic simulations using the micro-scale numerical model, ENVI-met 4v, applied in a case study of a Block in a highly residential neighbourhood of Athens. The study compares the bioclimatic scenarios of the roof top and road side vegetation plan in the current conditions, in order to evaluate how the existence of vegetation can affect the local air temperature and the thermal comfort condition of urban environment. This study also highlights the need to manage those microclimate data, through a geodatabase and provides a GIS approach of data organization and visualization. Creating building facades of the distributed temperature has showed that urban morphology parameters have an obvious impact on temperature distribution in the 3D space. On the other hand, the proposed roadside vegetation scenario has proved to be the most suitable way to improve the thermal comfort conditions of urban environment, as it can eliminate the Urban Heat Island (UHI) effects.
\end{abstract}

\section{INTRODUCTION}

The term «urban microclimate» signifies local variations in wind, humidity, solar radiation and temperature, influenced by urban morphology parameters (build infrastructures, vegetation, surface materials). Key factors, like the urban sprawl due to the rapid expansion of human population and the high temperatures of the frequent heat waves, of the last decades, affect the urban microclimate and the outdoor conditions of human comfort. Given the complexity of the urban environment and urban problems arising, the need for adaptation and change increasingly becomes important. The connection between the ecosystem and cities should subsist as a sustainable way of development. On the other side, the limited open spaces, the lack of green spaces, the high building density, the compactness of the Urban Blocks, the poor air quality and the traffic congestion can lead to the urban environmental degradation (Makropoulou, 2017). For that reason greening the cities, as part of bioclimatic concept of build environment, could be the way to decrease the outdoor temperature during hot days. A result of the abovementioned microclimate improvement technique (vegetation growth) would be the improvement of the outdoor thermal comfort conditions. Moreover, the existence of vegetation can contribute to cooling the urban environment through the evapotranspiration process. The shade of tree foliage can also control the solar radiation as the incident radiation is absorbed through photosynthesis process. (Dimoudi, et al., 2003).

Therefore, this paper is a step towards connecting the spatiotemporal distribution of the simulated urban air temperature with the façade of the buildings. The impact of urban air temperature on the façade of the building and how the gradation of temperature configures at 3D space, through three different vegetation scenarios are also analysed.

\section{RESEARCH BACKGROUND}

The urban sprawl, to which global warming is strictly related, has caused a series of environmental hazards that are wellknown but difficult to tackle. The Urban Heat Island effect (UHI) is one of them. The UHI is a phenomenon where a significant difference in temperature can be observed within a city or between a city and its suburbia and/ or its surrounding rural areas and areas of maximum temperature can expectedly be found within the densest part of the urban area (O'Malleya et al., 2015). Some of the most significant causes of UHI could be the anthropogenic heat emissions, pollution and energy consumption within a city (Santamouris et al., 2011), the reduced speed of wind caused by the structure of the built environment, the intensive land use and the high density in urban areas combined with buildings with high thermal masses and the heat retaining properties (Mavrogianni et al.,2011), lack of greenery and the presence of low-albedo materials on buildings external facades and road surfaces (O'Malleya et al., 2015).

The strategies to mitigate urban heat islands are divided into two categories - increasing urban albedo (reflectivity to solar radiation) and increasing evapotranspiration. Albedo increases are generally accomplished through high albedo roofing and paving technologies. Increase in evapotranspiration is accomplished through a combination of decreasing the fraction of impervious surfaces and planting vegetation in urban areas (shade trees, vegetated walls, and rooftop gardens/ ecoroofs) (Sailor, 2006).

Robinson (2001) describes a heat wave as an extended period of uncommon high atmosphere-related heat stress, which causes temporary modifications in lifestyle habits and adverse health 
related problems for affected residents and visitors. Thus, although a heat wave is a meteorological event, it cannot be assessed without reference to impacts on humans. An analysis of weather elements should always include the assessment of the human sensation of heat (Matzarakis and Nastos, 2006). A variety of heat stress indices that relate atmospheric conditions to human heat sensations have been developed so far. All thermal indices emphasize that the whole heat balance of the human body should be considered, which requires meteorological information about air temperature, air humidity, wind speed, turbulence, and short and long wave radiation in addition to the non-meteorological components of fitness and activity level, clothing type, and physiologic adaptation to a particular environment.

Results reported (Lazzarin et al., 2005, Onmura et al., 2001, Tang and Jiang, 2009), show that the total heat flux entering the building below the green roof was reduced by $60 \%, 50 \%$ and $73 \%$ respectively, compared to a conventional concrete roof without green roof irrespective of the weather conditions (Santamouris, M., 2014). Providing shade and evapotranspiration, trees and vegetation can lower the surface and air temperatures. Shaded surfaces, for example, may be 11$25^{\circ} \mathrm{C}$ cooler than the peak temperatures of unshaded materials (Akbari et al. 1997). Evapotranspiration, alone or in combination with shading, can help reduce peak summer temperatures by $1-5^{\circ} \mathrm{C}$ (Kurn et al. 1994). In hot and dry climates the increase of moisture in atmosphere through planting can reduce the temperature by up to 5 degrees, improving that way the sense of thermal comfort during summer (McPherson et al., 1999). Energy conservation benefits vary with tree location as well as size. Trees and vegetation are most useful as a mitigation strategy when planted in strategic locations around buildings or to shade pavement or streets. Researchers have found that planting deciduous trees to the west is typically most effective for cooling a building and providing an energy efficient building.

\section{MODELLING URBAN MICROCLIMATE}

Data collection techniques describing the typical urban microclimate of the study area are analyzed below. Moreover, the simulation process and the alternative scenario models are highlighted in combination with the techniques to manage and analyze that information through a GIS approach.

\subsection{Study Area and data collection}

The purpose of this study is to examine the effects of a highly densely built-up area to the urban microclimate. To this end, the study figures out how the air temperature and the thermal conditions vary based on low vegetated environment in residential area. For that reason, a Block in a built-up neighbourhood of Athens, Petralona has been examined. Its specific urban structure is the main reason of introducing it as case study area. According to statistics the Official Journal of the Hellenic Republic Government and the 2011 census data, the area of Petralona is characterized as over-populated with a density of 255 inhabitants per square kilometer. The population of that densely populated area is estimated to 130,000 inhabitants. In general, the profile of the area is characterized by limited vegetated areas with narrow streets adjacent to a crowded high way, source of pollutants. Given that, the feature under consideration and analysis is the block building element. Succeeding higher accuracy to the simulation, the adjacent area was also taken into account as parameter to the model. The surrounding building elements could be considered as barriers to the wind flow, affecting also to the shadow and further to the local temperature.

For the purpose of the simulation model, microclimatic data of the nearest meteorological station was used, in order to examine how the urban microclimate is created on current conditions and how the vegetation can improve the thermal comfort. Based on the climatic record of this station, relevant meteorological parameters have been considered in the analysis. These are the temporal variation of the temperature, the relative humidity, the wind speed and the wind direction of a typical day during summer (Table 1). For the volume construction of the building elements, the Digital Surface Model (DSM) of $80 \mathrm{~cm}$ and the Digital Elevation Model (DEM) of $5 \mathrm{~m}$ were used in combination with the footprint boundaries of each building (Figure 1). The courtyard is approximately $14400 \mathrm{~m}^{2}$ and completely surrounded by buildings of mean height of 15-18 m tall. Based on those microclimate parameters and to the structure of the urban morphology, three alternative vegetation scenarios were simulated through ENVI-met software (see section 3.2 and 3.3).

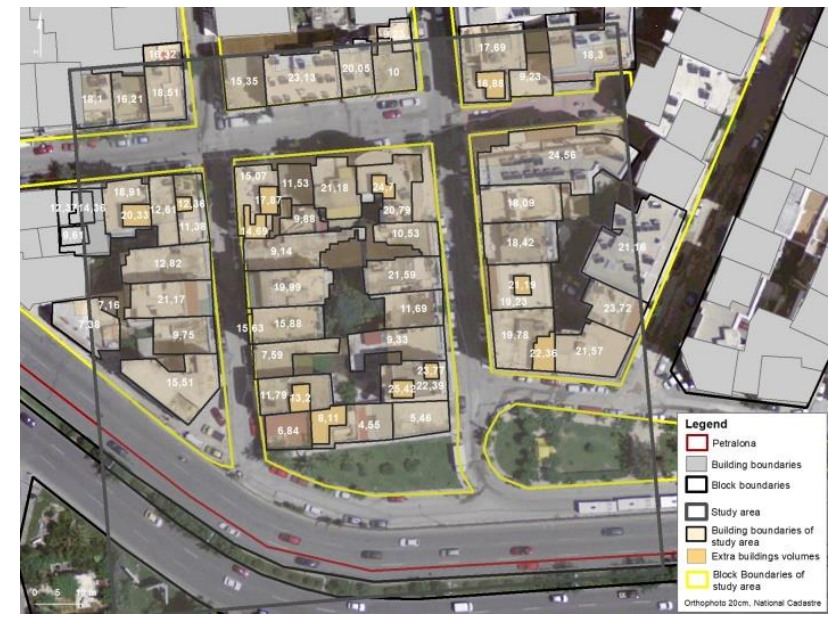

Figure 1: Building Heights of area

\begin{tabular}{|c|c|c|c|c|}
\hline Time & $\begin{array}{c}\text { Tempe- } \\
\text { rature }\left({ }^{\circ} \mathbf{C}\right)\end{array}$ & $\begin{array}{c}\text { Relative } \\
\text { humidity } \\
(\mathbf{\%})\end{array}$ & $\begin{array}{c}\text { Wind speed } \\
(\mathbf{m} / \mathbf{s e c})\end{array}$ & $\begin{array}{c}\text { Wind } \\
\text { direction }\end{array}$ \\
\hline 0:00:00 & 26.1 & 39 & 2.1 & 112.5 \\
\hline 1:00:00 & 25.5 & 44.5 & 3 & 0 \\
\hline $2: 00: 00$ & 25.1 & 47 & 3.1 & 67.5 \\
\hline $3: 00: 00$ & 24.8 & 42 & 0 & 315 \\
\hline $4: 00: 00$ & $\mathbf{2 4 . 5}$ & 42 & 0 & 292.5 \\
\hline $5: 00: 00$ & 27.5 & 43.5 & 2.5 & 180 \\
\hline $6: 00: 00$ & 31.2 & 42 & 0 & 337.5 \\
\hline $7: 00: 00$ & 32.9 & 39.5 & 0 & 337.5 \\
\hline $8: 00: 00$ & 34.2 & 39 & 0 & 337.5 \\
\hline $9: 00: 00$ & 35.6 & 38 & 4.7 & 157.5 \\
\hline $10: 00: 00$ & 36.6 & 38 & 3 & 112.5 \\
\hline $11: 00: 00$ & 37 & 37.5 & 0.8 & 180 \\
\hline $12: 00: 00$ & 37 & 37 & 0 & 180 \\
\hline $13: 00: 00$ & $\mathbf{3 7 . 4}$ & 37 & 0 & 112.5 \\
\hline $14: 00: 00$ & 37 & 36 & 2.9 & 135 \\
\hline $15: 00: 00$ & 35.4 & 36 & 0 & 180 \\
\hline $16: 00: 00$ & 34.3 & 38 & 1.1 & 180 \\
\hline $17: 00: 00$ & 33.3 & 39 & 3.6 & 180 \\
\hline $18: 00: 00$ & 32.1 & $\mathbf{3 2}$ & 3.2 & 180 \\
\hline $19: 00: 00$ & 31.3 & 33 & 0 & 45 \\
\hline $20: 00: 00$ & 31 & 35 & 0 & 180 \\
\hline $21: 00: 00$ & 29.5 & 41 & 3 & 45 \\
\hline & & & & \\
\hline
\end{tabular}




\begin{tabular}{|c|c|c|c|c|}
\hline 22:00:00 & 27.9 & 44 & 0 & 45 \\
\hline $23: 00: 00$ & 27.1 & $\mathbf{5 0}$ & 0 & 337.5 \\
\hline
\end{tabular}

Table 1: Meteorological parameters of simulation day

\subsection{Simulation of Urban Microclimate}

The different proposed Bioclimatic - mitigation Scenarios were investigated through microclimatic simulations using the microscale numerical model, ENVI-met. ENVI-met simulates the temporal evolution of several thermodynamics parameters on a micro-scale range, creating a $3 \mathrm{D}(2 \times 2 \times 2$ grid cell in meters), non-hydrostatic model of the interactions between buildingatmosphere-vegetation (Berardi, et al. 2016). With its physical fundamentals that are based on the principles of fluid mechanics, thermodynamics and the laws of atmospheric physics it is able to calculate three dimensional wind fields, turbulence, air temperature and humidity, radiative fluxes and pollutant dispersion (Bruse, 1999). The high spatial resolution of the model combining with the detailed modeling of vegetation allows the simulation of the individual photosynthesis rates taking into account the local solar radiation, the air temperature and humidity, the wind speed, the $\mathrm{CO}_{2}$ concentration and many other parameters (Bruse, 2004b, Simon, 2016).

The flowchart in Figure 2 illustrates the methods used in this work in order to simulate the microclimate parameters through ENVI-met. The methodology process followed included three main stages:, firstly, the organization through the file directory, secondly, modelling and editing the simulation parameters (microclimate data and build elements) using the database of the plants and surface materials creating the area input file (.INX) and the simulation file (.SIM) and finally the assessment of the outcome files (.EDT/EDX) and their visualization.

Thermal comfort is referred as an indicator to describe people's subjective experience of temperature in urban open spaces. For that reason, the analysis focuses also to the thermal comfort feeling a dense structured urban environment in order to analyse and describe how the proposal vegetation scenarios can improve it. Given Figure 2, ENVI-met software simulates firstly the microclimates' data and then estimates the selected thermal comfort index, through the Predicted Mean Vote (PMV) index. PMV index evaluates the outdoor thermal comfort and summarizes the impact of the 4 main atmospheric variables: Air Temperature, Radiative Temperature, Wind Speed and Humidity on the human thermal sensation. Calculating the PMV index is taken also into account variables referring human characteristics, such as a 35 year old male with $75 \mathrm{~kg}$ weight and $1.75 \mathrm{~m}$ height, reacting on clothing parameters and body metabolism (ENVI-met Development Team, 2014). The index values range between -4 (cool conditions) and +4 (hot conditions), while 0 value is characterized as neutral thermal comfort conditions. Sometimes, the index values can be varying, as the PMV model is based on Fanger (1972) comfort model and relates the energy balance of the human body with the human thermal impression.

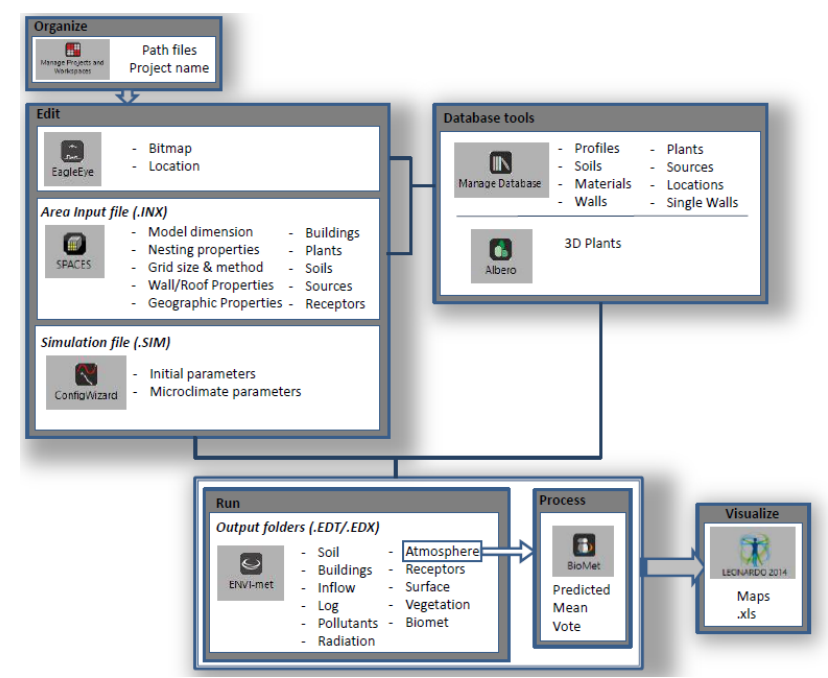

Figure 2: ENVI-met workflow

As already referred on section 3.1, for the purpose of this study, a Block in a highly residential neighbourhood of Athens, Petralona has been examined. In order to model the area's microclimate conditions and to examine UHI mitigation scenarios, one of the hottest days in 2016 was selected. Regarding the peak values of the simulation, the recorded temperature for July was $37.4{ }^{\circ} \mathrm{C}$ at $13: 00 \mathrm{~h}$ during summer (Table 2). The purpose of modelling that area is to examine how vegetation can affect to the reduction of local temperature. For that reason, all the main parameters described on Table 2 and Table 3 in the simulation, such as the range of the temperature, the humidity, the speed, the direction of the wind but also the characteristics of the build environment (absorption, reflection, albedo, emissivity of the roads, soil and building materials) remained unchanged, in order to evaluate only the effect of the described vegetation scenarios (section 3.3) on the urban microclimate (Ambrosini, et. al 2004).

The ENVI-met model basically consists of a one-dimensional boundary model, that includes vertical profiles of different meteorological parameters up until a height of 2500 meters and a three dimensional core model that includes all atmosphere, soil, building and vegetation processes. The $1 \mathrm{D}$ boundary model generates one-dimensional profiles for meteorological parameters such as air temperature, specific humidity and wind vectors (horizontal) for each vertical profile. The size of the model areas highly depends on the spatial resolution of the model. For that reason, the extent of the total area modified to fit to the grid extent of the basic ENVI-met model. The simulation grid was $60 \times 60$ cells horizontally and 30 cells vertically, with cell size $2 \times 2 \times 2$ resulting to a total area size of 120x120x60 meters. The simulated total area was about $14400 \mathrm{~m}^{2}$. This resolution allows analysing small-scale interactions between individual buildings, surfaces and plants for the different scenarios into a period of 24 hours.

The cells on each vertical grid follows the equidistant method having the same dimensions, except for the lower one divided into 5 substrates with $\mathrm{dzs}=0.2 * \mathrm{dz}$, namely profile layers per $\mathrm{dzs}=0,4 \mathrm{~m}$. The nesting area surrounds the core model, gives stable lateral boundary conditions for the core model (Bruse, 1999) but it is not part of the computational space of the model. Using 6 cells for every dimension in space, the simulations' computational power is improved as the model boundaries are extended. 
Each cell is defined by its physical properties of the urban environment, such as surface materials, plants and built infrastructure materials. ENVI-met databases provide a variety of materials and 3D plants allowing the detailed reconstruction of an accurate modelling of the urban environment. Each material type is defined by the specific heat capacity, absorption, albedo and other parameters. Figure 3 and Table 3 and also Table 4 for the plants; illustrate all the selected materials that used to construct the area model. Figure 3 proves that the urban environments are generally characterized by high albedo surfaces (surface materials) and sparsely vegetated areas of open space and roadside vegetation.

\begin{tabular}{|lc|}
\hline \multicolumn{3}{|c|}{ Simulation Input Data } \\
\hline Simulation Model Size (m) & $120 \times 120 \times 60$ \\
\hline $\begin{array}{l}\text { Model Area (Number of Grids) } \\
\text { xyz-Grids }\end{array}$ & $60 \times 60 \times 30$ \\
\hline Size of grid cell (meters) dx,y,z & $2 \times 2 \times 2$ \\
\hline $\begin{array}{l}\text { Geographic Location } \\
\text { (Latitude, Longitude) }\end{array}$ & $37.96,23.70$ \\
\hline Nesting grids & 6 \\
\hline Method of vertical grid generation & Equidistant \\
\hline Reference time zone & GMT+2 \\
\hline \multicolumn{2}{|c|}{ Main model parameters } \\
\hline Simulation Date & $24 \mathrm{July} 2016$ \\
\hline Start \& Duration of Simulation & $00: 00,24 \mathrm{~h}$ \\
\hline Wind speed measured in 10m height & $2.1 \mathrm{~m} / \mathrm{s}$ \\
\hline Wind direction & $112.5^{\circ}$ \\
\hline Initial Temperature of atmosphere & $26.1^{\circ} \mathrm{C}=299.25 \mathrm{~K}$ \\
\hline Min Temperature (simulation date) & $24.5^{\circ} \mathrm{C}, 4: 00 \mathrm{~h}$ \\
\hline Max Temperature (simulation date) & $37.4^{\circ} \mathrm{C}, 13: 00 \mathrm{~h}$ \\
\hline Relative Humidity in 2m height (\%) & $39 \%$ \\
\hline $\begin{array}{l}\text { Specific humidity at model top } \\
\text { (2500m, g/kg) }\end{array}$ & $7 \mathrm{~g} / \mathrm{kg}$ \\
\hline Min humidity (simulation date) & $32 \%, 18: 00 \mathrm{~h}$ \\
\hline Max humidity (simulation date) & $50 \% 23: 00 \mathrm{~h}$ \\
\hline
\end{tabular}

Table 2. Input Data of the study area in ENVI-met

\begin{tabular}{|ll|c|}
\hline \multicolumn{2}{|c|}{ Element type } & Albedo \\
\hline$[\mathrm{C} 5]$ & Concrete wall (cast dense) & 0.3 \\
\hline$[\mathrm{ST}]$ & Asphalt Road & 0.2 \\
\hline$[\mathrm{PP}]$ & Pavement (Concrete) & 0.4 \\
\hline$[\mathrm{PG}]$ & Concrete pavement gray & 0.5 \\
\hline$[\mathrm{KK}]$ & Brick road (red stones) & 0.3 \\
\hline$[\mathrm{LO}]$ & Loamy Soil & 0.0 \\
\hline
\end{tabular}

Table 3: Element types of build environment
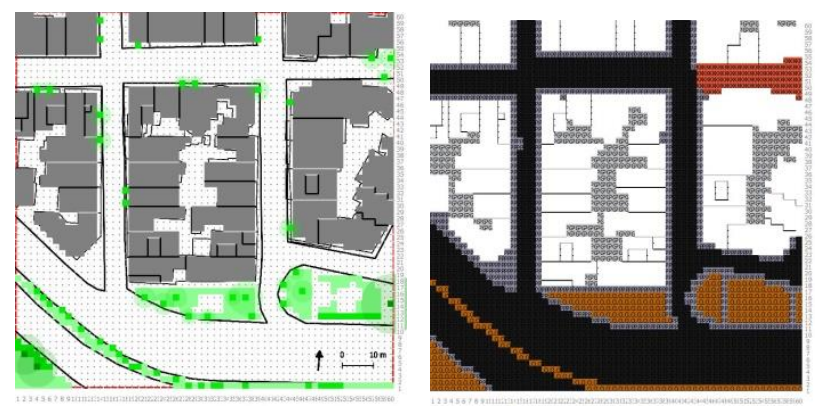

Figure 3: Material types of the study area.

Land cover materials (right), materials of the structured environment and vegetation (left) - (2D View).

\subsection{Vegetation scenarios of bioclimatic strategy}

The mitigation strategies of the high temperatures of the urban canopy which have been selected for evaluation within that research project follow the principles of bioclimatic design. As already mentioned vegetation can mitigate extreme temperatures and provide better conditions of thermal comfort. For that reason, two alternative scenarios are compared with the current status conditions of the area model. Specifically, the models referred firstly to the current conditions (non-vegetation proposed) and secondly to the two alternatives, one of a roadside vegetation plan and one of a roof top greening. The database of ENVI-met consists of 3D plants and was applied on those two alternative scenarios in order to boost the vegetated covers of the roads and roofs. Based on Table 4 the plants located in a way to take advantage of their special type and use in order to address urban heat stress and thermal discomfort, calibrating energy balance and eliminating the noise pollution of the highway on the south of the examining area.

Shading the area, protecting it from atmospheric pollution and finally from wind are the main reasons of using vegetation as a mitigation strategy. In addition, trees shadow can also result in an increase in albedo over the other material surfaces (e.g., asphalt roads). As the shortwave radiation reaches the surface in the urban environment it is partially absorbed and partially reflected. The low albedo value of the vegetation (Table 4) provides that the incoming solar radiative heat flux is absorbed in an extent, contributing to the reduction of the temperature and to the improvement of the thermal environment through evapotranspiration processes. Depending on the period of time, evergreen or deciduous trees can be proved useful to the build environment. Based on the principle of bioclimatic design, the south side of the building should be used for passive solar heating, while the North side, for wind protection in winter and heat reduction though cooling, during summer months. Hence, the deciduous trees should be planted to the South, providing maximum solar coverage in winter and shade during summer. On the contrary, evergreen trees should be plant to the North yielding to a permanent shading of the surface throughout the year.
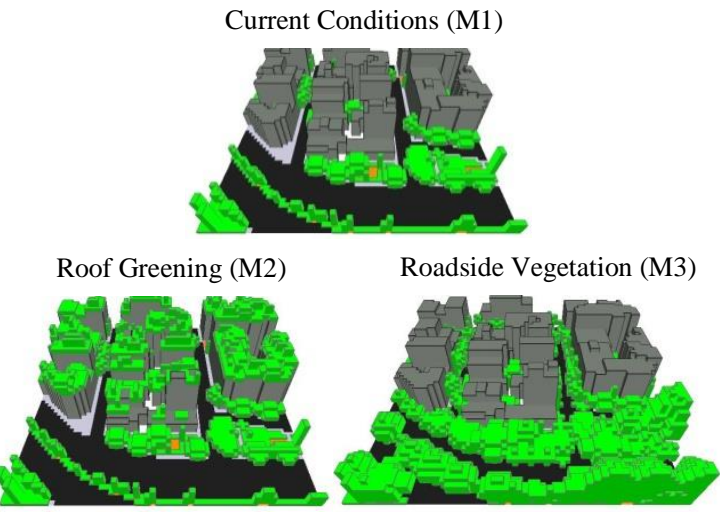

Figure 4. Simulated Scenarios of vegetation in Envi-met (3D View)

\begin{tabular}{|l|c|c|c|c|c|}
\hline Code & Latin Name & $\begin{array}{c}\text { Height, } \\
\text { Width }\end{array}$ & Albedo & Type & Use \\
\hline$[\mathrm{OT}]^{*}$ & Olive tree & 4,5 & 0.50 & $\mathrm{E}$ & $\mathrm{AP}$ \\
\hline$[03]^{*}$ & $\begin{array}{c}\text { Robinia } \\
\text { pseudoacacia }\end{array}$ & 12,7 & 0.18 & $\mathrm{E}$ & $\mathrm{S}$ \\
\hline$[\mathrm{A} 4]^{*}$ & black locust & 22,13 & 0.18 & $\mathrm{E}$ & $\mathrm{S}$ \\
\hline$[\mathrm{Z}]^{*}$ & Citrus Aurantium & 4,3 & 0.40 & $\mathrm{E}$ & $\mathrm{AP}$ \\
\hline
\end{tabular}




\begin{tabular}{|l|c|c|c|c|c|}
\hline$[\mathrm{AC}]^{*}$ & Acacia & 2,3 & 0.60 & $\mathrm{D}$ & $\mathrm{AP}$ \\
\hline$[\mathrm{AJ}]^{*}$ & Albizia Julibrissin & 12,11 & 0.60 & $\mathrm{D}$ & $\mathrm{AP}$ \\
\hline$[\mathrm{AN}]$ & Acer negundo & 11,9 & 0.50 & $\mathrm{D}$ & $\mathrm{S}$ \\
\hline$[\mathrm{LI}]$ & Ligustrum & 5,5 & 0.40 & $\mathrm{D}$ & $\mathrm{W}$ \\
\hline$[\mathrm{PN}]$ & Populus Nigra & 20,15 & 0.40 & $\mathrm{D}$ & S/W/AP \\
\hline$[\mathrm{PA}]$ & Populus Alba & 7,5 & 0.70 & $\mathrm{D}$ & S/W/AP \\
\hline$[07]$ & Acer platanoides & 15,7 & 0.18 & $\mathrm{D}$ & W/AP \\
\hline$[02]$ & Tilia platyphyllos & 22,15 & 0.18 & $\mathrm{D}$ & S/W/AP \\
\hline$[\mathrm{S} 2]$ & Sophora Japonica & 10,15 & 0.60 & $\mathrm{D}$ & S/AP \\
\hline$[\mathrm{S} 3]$ & Sophora Japonica & 15,23 & 0.60 & $\mathrm{D}$ & S/AP \\
\hline$[\mathrm{S} 1]$ & Sophora Japonica & 5,9 & 0.60 & $\mathrm{D}$ & S/AP \\
\hline$[\mathrm{B} 9]^{*}$ & Palm & 6,5 & 0.60 & & \\
\hline$[\mathrm{PS}]$ & Phoenix small & 7,7 & 0.60 & & \\
\hline$[\mathrm{NC}]^{*}$ & $\begin{array}{c}\text { Square Tree - } \\
\text { Low }\end{array}$ & 5,7 & 0.60 & & \\
\hline$[\mathrm{NB}]$ & $\begin{array}{c}\text { Squre Tree - } \\
\text { Middle }\end{array}$ & 10,9 & 0.60 & & \\
\hline$[\mathrm{T} 1]^{*}$ & $\begin{array}{c}\text { Tree very dense, } \\
\text { leafless base }\end{array}$ & 10 & 0.2 & & \\
\hline$[\mathrm{SK}]$ & $\begin{array}{c}\text { Tree very dense, } \\
\text { distinct crown } \\
\text { layer }\end{array}$ & 15 & 0.2 & \multicolumn{2}{|l}{} \\
\hline$[\mathrm{GB}]^{*}$ & Grass aver, dense & 50 & 0.2 & \multicolumn{2}{|l}{} \\
\hline$[\mathrm{H} 2]^{*}$ & Hedge dense & 2 & 0.2 & \multicolumn{2}{|l}{} \\
\hline & & &
\end{tabular}

Type: Evergreen or Deciduous

Use: S: Shadow, W: Windbreak, AP: Atmospheric Pollution

*Plant types of current condition status

Table 4: Types of Vegetation scenarios

\subsection{Integrating GIS and environmental simulation model}

Regarding the management and the visualization of the simulated microclimate data into the abovementioned study area, ArcMap (ESRI) was used to create a geospatial database. The flowchart in Figure 4 illustrates the approach idea used for creating the geospatial database. That approach aims to integrate the simulated microclimate data of ENVI-met into a GIS environment in order to accomplish both a computational evaluation of the model and the façade's visualization of the outdoor temperature. The methodology process included three main stages:, firstly, the creation of the model that consist the extraction of the building heights and the simulated models of ENVI-met, secondly the format transformation of the microclimate data to a GIS adaptable format, in order the information to get connecting with the building elements. Finally, the assessment of the outcome products became through their visualization in 2.5D Views and 2D Views.

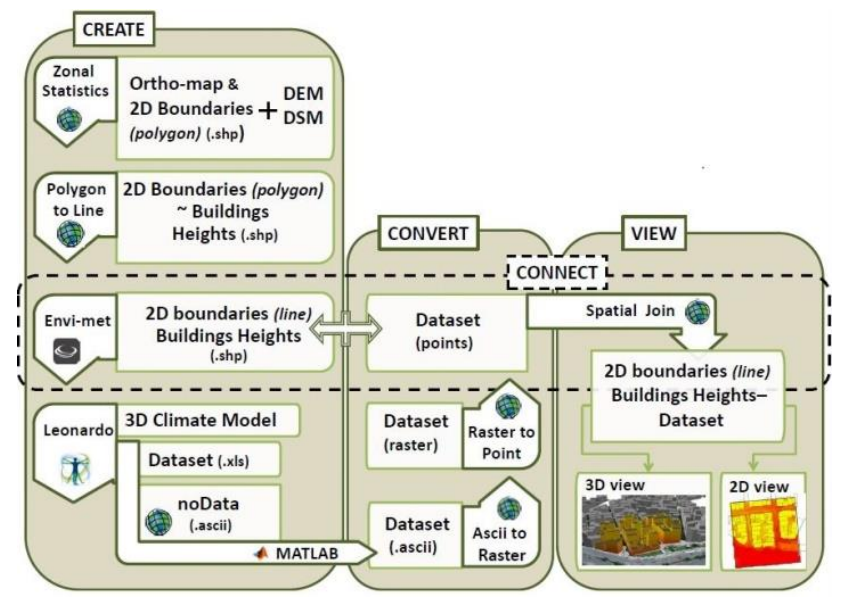

Figure 4. Study workflow
The $\mathrm{z}$ dimension of the simulated outdoor temperature is considered as an extra information column into the attribute table of the geodatabase. Given the workflow in Figure 4 it is important to underline that the height of the buildings was extracted using the zonal statistics function of the Spatial Analyst tools in GIS. The extruded volume was provided by subtracting the Digital Elevation model (DEM) from the Digital Surface Model (DSM) and calculating the average of all cells of the output raster that belong to the same zone (building footprint polygon) (Figure 1). Those polygons of the building boundaries were converted into lines' geometry form. The façade of the buildings was referred to that line geometry in which the information of the simulated microclimate data was connected in order to visualize it in GIS. The script in Matlab, provided by Liming Zhang, helped to convert Leonardo`s output data of ENVI-met software (.xls format) to ASCII format. GIS contributed also to the management of the output of the simulated temperature (in .ascii format), converting them into a raster dataset for every $2 \mathrm{~m}$ of the $3 \mathrm{D}$ model. Converting those raster datasets of every $2 \mathrm{~m}$ of the vertical space into similar point datasets, was easy to acquire all the nearest points to the façade of the buildings. In this way, connecting the temperature values of those points to every side of the linear footprint of the building, temperature zones were created for every $2 \mathrm{~m}$ of the building volume (Figure 5). Furthermore, ArcScene was used for the 2.5D visualization of LoD1 buildings, generating facades with vertical distribution of the outdoor temperature.

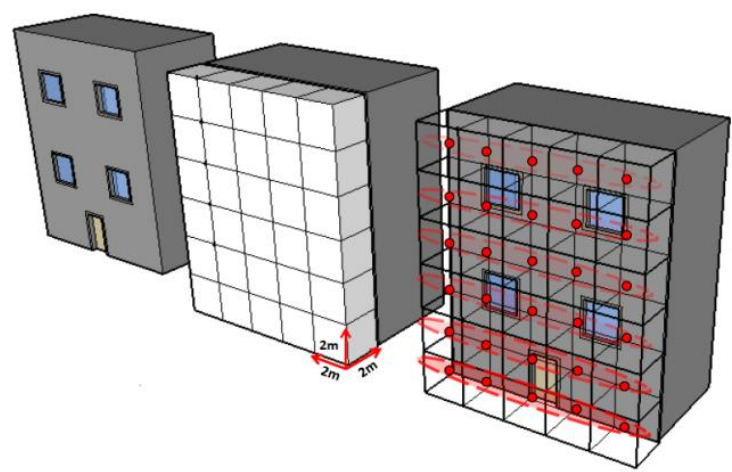

Figure 5. Integrating simulation data into GIS database

The need to automate in a way the above process of managing those extended datasets of the three alternative scenarios was accomplished through the ModelBuilder tool of ArcGIS. ModelBuilder could be thought as a visual programming language for building workflows. The workflow chart in Figure 6 illustrates the iteration process for each model, resulting to the connection of the simulated information with the building's facade of the study area.

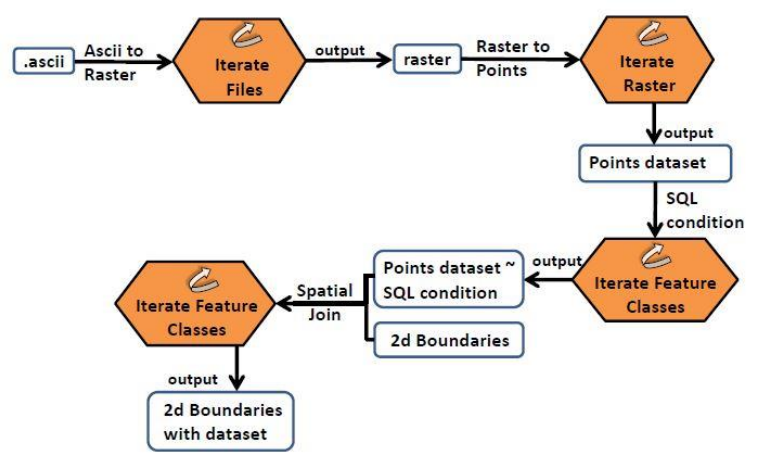

Figure 6: Iteration process through ModelBuilder 


\subsection{Results}

This paper evaluated urban reconstruction, based on the bioclimatic concepts of urban planning. On Figure 7, the current status of the area (left side) proved that the high albedo surfaces of the urban structure leads to increase the urban heat stress. Moreover, results show that combining the microclimate data, of the maximun temperature at $37.4{ }^{\circ} \mathrm{C}$ with the urban material surfaces and into that urban morphology can lead to extreme heat waves of $39-41^{\circ} \mathrm{C}$. Having a roadside vegetation model seems that those extreme temperature values can be locally decreased (Figure 7, right part). As evidenced by subtracting the temperatures of the roadside vegetation from that of initial urban conditions (Figure 8, left and right part), the simulation results showed that the roadside vegetation scenario is characterized as the most effective heat mitigation strategy for the local microclimate of this case study. Road side planning as heat mitigation strategy provided that the conditions near the façade of the builings may be 0.25-1.28 degrees cooler, where plants exist. The roof top green scenario did not contribute to a significant microclimate improvement on the façades of the builiding compared to the initial urban conditions (Figure 8, lower part). Those results on the rooftop greening model shows that the outdoor air temperature near façades may be stable, but can reduce it on the top of each building up to 0.85 degrees (Figure 9, right part).
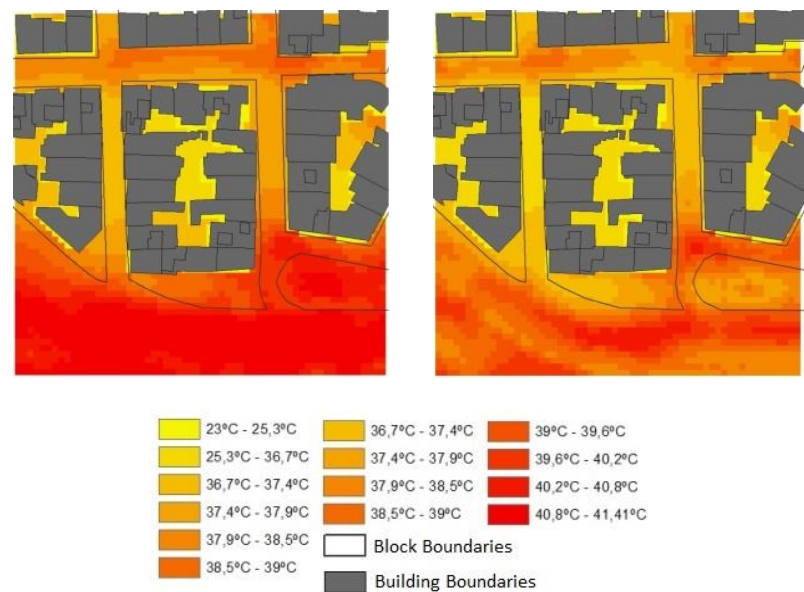

Figure 7: 2D View ( $0.2 \mathrm{~m}$ height) of the air Temperature in the study area

(left - current conditions), (right - roadside vegetation)

The compared values between the mitigation strategy models and the current condition model of the Predicted Mean Vote (PMV) index are illustrated on Figure 9. On the left side of the figure, the existence of roadside vegetation seems to improve the thermal comfort conditions on roads but the green roof on the right side contributes to reduce the temperature on the top of the buildings. Specifically, the estimated PMV at $0.4 \mathrm{~m}$ height (mean height for human motion) connects the conditions of roadside vegetation with the improvement of the thermal confort up to 5 in the PMV scale. Furthermore, the same model seems to reduce in some way the temperature on the top of the building by 0.34 degrees. According to the indicated PMV of roof top vegetation, the green roofs may did not provide the expected decline on thermal confort values (reduced up to 1 on the PMV scale) but mitigate the heat stress on the top of the buildings by 0.85 degrees. As a result, the study was shown that urban morphology parameters have a significant connection with microclimate variables. In other words, urban morphology parameters have an obvious impact on temperature distribution in the 3D space. On that base, the outdoor temperature gradation on the building's façade was obvious, with the temperature being higher at lower levels.
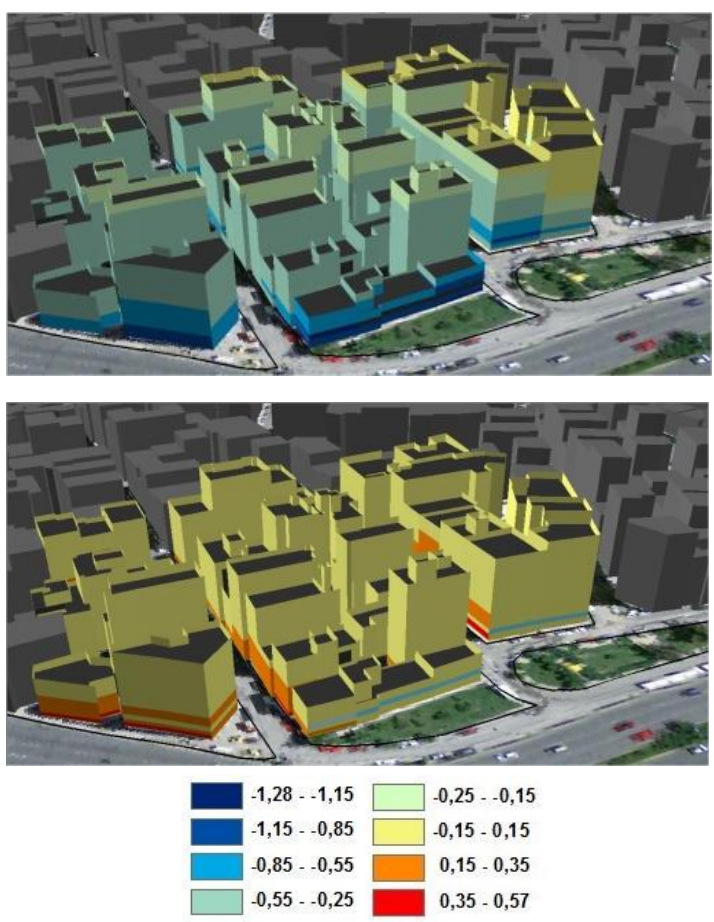

Figure 8: Disturbing temperature on façades between the alternative models (upper - Difference M1-M3), (lower - Difference M1-M2)
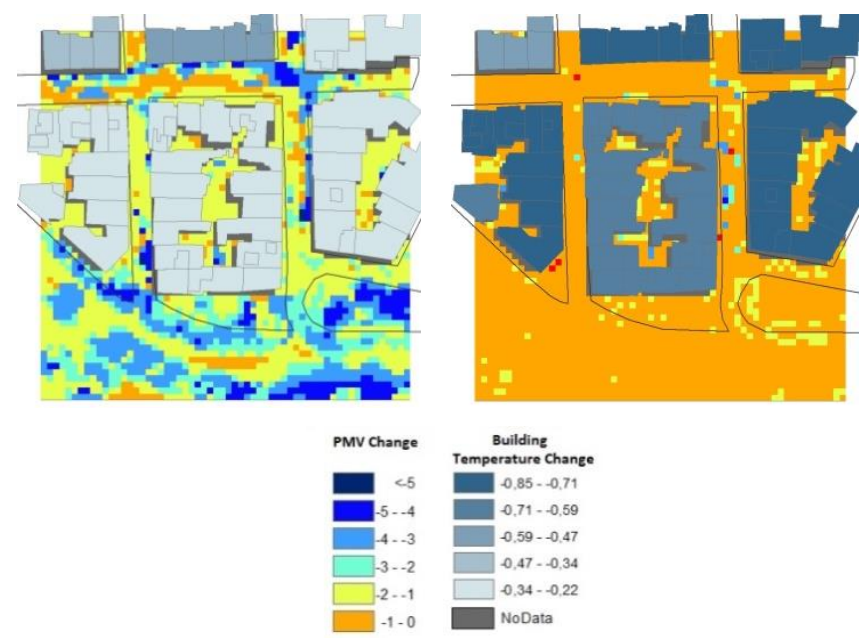

Figure 9: Distribution of differences in thermal comfort values for the height of $0.4 \mathrm{~m}$ from the ground (mean height for human motion) (left side - Difference M1-M3), (right side - Difference M1-M2) 


\section{CONCLUSIONS AND FUTURE RESEARCH}

Many urban mitigation and adaptation strategies have been proposed to cope with UHI to eliminate extreme temperature values during summer. Roadside vegetation and roof top greening applied to this study seems to provide significant potentials to mitigate UHI effects. Analysis of thermal comfort index proved also that special selection of plant types can contribute to improve the pedestrians' thermal conditions. The most efficient model proved to be the one with the roadside vegetation. In order to access higher accuracy and more effective results, a multi-disciplinary approach of a dynamic spatio-temporal analysis should be applied. On the basis of the bioclimatic concept of planning, a variety of surface materials and materials of build infrastructure with different properties, such as albedo, emission and absorption rate can be applied in combination with variety of evergreen and deciduous trees of different height.

Assessing the value, the need and difficulties to manage the simulated data into a geospatial database was the main drive of using GIS platform to construct a three-dimensional space. The software integration of ENVI-met and ArcMap, offers a hybrid visualized application of the simulated outdoor temperature which can be further analysed using higher level of details (LoD) through the open standardized data model, CityGML (OGC 12-019, 2012). CityGML, as a 3D city model, would refine the results by providing geometrical, topological and semantical 3D features and city objects (such as buildings, roads, rivers, bridges, vegetation and city furniture) and the relationships between them.

Application domains that CityGML would develop this work include among others the estimation of building energy demand, shadows for evaluating the heat demands and the building retrofit and also the construction of green areas for urban planning perspectives. Finally, since microclimate parameters are influenced by surfaces and volumes, a detailed 3D modelling through CityGML, would provide other buildings and the territorial morphology, thus better determining the buildings' energy efficiency (Dalla Costa, et. al., 2011).

\section{REFERENCES}

Akbari, H., Kurn, D., 1997. Peak power and cooling energy savings of shade trees. Energy and Buildings 25:139-148.

Ambrosini, D., Galli, G., Mancini, B., Nardi, I., Sfarra, S., 1, 2014. Evaluating Mitigation Effects of Urban Heat Islands in a Historical Small Center with the ENVI-Met ${ }^{\circledR}$ Climate Model. Sustainability 2014, 6(10), 7013-7029;

http://www.mdpi.com/2071-1050/6/10/7013

Berardi, U., Wang, Y., 2016. The Effect of a Denser City over the Urban Microclimate: The Case of Toronto. Sustainability 2016 8(8), 822; doi: https://doi.org/10.3390/su8080822

Bruse, M. 1999. Die Auswirkungen kleinskaliger Umweltgestaltung auf das Mikroklima. Entwicklung des prognostischen numerischen Modells ENVI-met zur Simulation der Wind-, Temperatur- und Feuchteverteilung in stadtischen Strukturen. Dissertation, Ruhr-Universitat Bochum
Bruse, M., 2004. ENVI-met implementation of the Jacobs A gs Model to calculate the stomata conductance http://envimet.com/documents/new_a_gs.pdf.15.04.2015, 2004b.

Dalla Costa, S., Roccatelloa, E., Rumora, M., 2011. A CityGML 3D Geodatabase for buildings' energy efficiency. In: ISPRS Archives of the Photogrammetry, Remote Sensing and Spatial Information Sciences, Volume XXXVIII-4/C21. In Proceedings of 28th Urban Data Management Symposium, Sept. 2011, Delft, The Netherlands

Dimoudi, A., Nikolopoulou, M., 2003. Vegetation in the Urban Environment. Energy and Buildings. https://doi.org/10.1016/S0378-7788(02)00081-6

ENVI-met Development Team, 2014. Using ENVI-met BioMet. http://www.envi-met.info/doku.php?id=apps:biomet

Gröger, G., Kolbe, T.H., Nagel, C., Häfele, K.H., 2012. OGC City Geography Markup Language (CityGML) Encoding Standard, Open Geospatial Consortium

Kurn, D., S. Bretz, B. Huang, and H. Akbari. 1994. The Potential for Reducing Urban Air Temperatures and Energy Consumption through Vegetative Cooling. ACEEE Summer Study on Energy Efficiency in Buildings, American Council for an Energy Efficient Economy. Pacific Grove, California.

Makropoulou, M. 2017. Microclimate Improvement of InnerCity Urban Areas in a Mediterranean Coastal City. Sustainability 2017, 9, 882; doi: 10.3390/su9060882

Matzarakis, A, Nastos, P., 2006. HEAT WAVES IN ATHENS. In 8th Conference on Meteorology - Climatology Atmospheric Physics, Athens, http://www.urbanclimate.net/matzarakis/papers/2008_heatwave sathnes_comecap2006.pdf .

McPherson E.G., Simpson J.R., Peper P.J. and Xiao Q., 1999. Tree Guidelines for San Joaquin Valley Communities. USDA For. Service, Pacific Southwest Research Station.

O’Malleya, C., Piroozfarb, P., Farrc, E., Pomponib, F. 2015 Urban Heat Island (UHI) mitigating strategies: A case-based comparative analysis. In Sustainable Cities and Society 19(2015)222-235

Sailor, D. J., 2006. Mitigation of Urban Heat Islands Recent progress and future prospects. Portland State University https://www.coolrooftoolkit.org/wp-

content/uploads/2012/04/Mitigation-of-Urban-Heat-Islands.pdf

Santamouris,M., Synnefa,A., Karlessi,T.,2011.Using advanced cool materials in the urban built environment to mitigate heat islands and improve thermal comfort conditions. In Solar Energy, 85(12), 3085-3102.

Santamouris, M., 2014. Cooling the cities - A review of reflective and green roof mitigation technologies to fight heat island and improve comfort in urban environments. In Solar Energy, Volume 103, 2014, Pages 682-703

Simon, H., 2016. Development, implementation and evaluation of new and improved calculation methods for the urban microclimate model ENVI-met. Dissertation zur Erlangung des Grades "Doktor der Naturwissenschaften" im Promotionsfach 
The International Archives of the Photogrammetry, Remote Sensing and Spatial Information Sciences, Volume XLII-4, 2018 ISPRS TC IV Mid-term Symposium “3D Spatial Information Science - The Engine of Change”, 1-5 October 2018, Delft, The Netherlands

Geographie am Fachbereich Chemie, Pharmazie und Geowissenschaften der Johannes Gutenberg-Universitat Mainz 